\title{
Analisa Risiko Rantai Pasok Lopo Mandailing Kopi dengan Pendekatan Sistem Traceability
}

\author{
Misra Hartati ${ }^{1}$, Abdul Rahman ${ }^{2}$ \\ ${ }^{1,2}$ Jurusan Teknik Industri, Fakultas Sains dan Teknologi, UIN Sultan Syarif Kasim Riau \\ Jl. HR. Subrantas No.155 Simpang baru Pekanbaru 28293 \\ Email : misrahartati@uin-suska.ac.id, hasibuanrahman90@gmail.com
}

\begin{abstract}
Abstrak
Lopo Mandailing Kopi adalah sebuah nama produk kopi yang diproduksi oleh UKM KUB Perintis Harapan Mandailing Natal Sumatera Utara dengan Jenis kopi yang diproduksi adalah Arabica. Setiap aktivitas yang dilakukan oleh perusahaan termasuk sistem distribusi tidak akan terlepas dari ketidakpastian atau kejadian peristiwa tak terencana yang bisa mempengaruhi aliran bahan dan komponen pada rantai pasok (Svensson, 2000 dikutip oleh Handayani, 2013). Ketidakpastian dan dampak dari suatu peristiwa didalam rantai pasok dapat dikatakan dengan risiko (Sinha, 2004 dikutip oleh Handayani, 2013). Risiko tidak dapat dihindari akan tetapi dapat diminimalisir atau dihilangkan dengan melakukan penanganan risiko yang tepat. Lopo Mandailing Kopi ini sendiri memiliki struktur rantai pasok yaitu petani, pemasok, pabrik dan distributor. Permasalahan di perusahaan ini adalah seringnya terjadi risiko pada rantai pasok baik dia risiko cacat pada bahan baku maupun produk, sehingga perlu dilakukan identifikasi terhadap aktivitas rantai pasoknya untuk mengetahui apa saja risiko yang terjadi, dimana risiko tersebut terjadi dan apa penyebab risiko tersebut terjadi. Penelitian ini mengggunakan metode pendekatan sistem traceability dan dibantu dengan metode Supply Chain Operation Reference (SCOR). Traceability merupakan suatu sistem yang dapat meningkatkan transparansi dalam rantai supplai dalam mengurangi risiko klaim serta menemukan potensi risiko proses rantai pasok makanan (Liu, 2002 dikutip oleh Jaya, 2014). Berdasarkan identifikasi maka diperoleh total 29 kejadian risiko dari seluruh rantai pasok. Dan sesuai konsep 80:20 diagram pareto, maka terdapat 16 penyebab risiko yang menjadi prioritas untuk dilakukan penanganan.
\end{abstract}

Kata kunci: Analisa Risiko, Traceability, SCOR

\section{Latar Belakang}

Perusahaan harus mulai waspada dan mau berubah dalam mengelola dan mengoperasikan supply chainnya agar dapat beradaptasi dengan kebutuhan perusahaan. Disamping itu perusahaan perlu mengetahui faktor-faktor utama yang berpengaruh terhadap kelancaran supply chain dan resiko-resiko yang mungkin terjadi (Utari dkk, 2015). Setiap aktivitas yang dilakukan oleh perusahaan termasuk sistem distribusi tidak akan terlepas dari ketidakpastian atau kejadian peristiwa tak terencana yang bisa mempengaruhi aliran bahan dan komponen pada rantai pasok (Svensson, 2000 dikutip oleh Handayani, 2013). Ketidakpastian dan dampak dari suatu peristiwa didalam rantai pasok dapat dikatakan dengan risiko (Sinha, 2004 dikutip oleh Handayani, 2013). Risiko ini merupakan faktor-faktor yang menghambat operasional pada rantai pasok makanan, yang mana risiko pada rantai pasok dapat terjadi mulai dari hulu pemasok, pabrik, distribusi, dan sampai hilir distributor, konsumen. Risiko lebih dikaitkan dengan kerugian yang diakibatkan oleh kejadian yang mungkin terjadi dalam waktu tertentu (Jutner, 2003 dikutip oleh Handayani, 2013). Risiko tidak dapat dihindari akan tetapi dapat diminimalisir atau dihilangkan dengan melakukan penanganan risiko yang tepat. Biasanya, satu penyebab risiko dapat merangsang lebih dari satu kejadian risiko (Pujawan dkk, 2009 dikutip oleh Handayani, 2013).

Lopo Mandailing Kopi adalah sebuah nama produk kopi yang diproduksi oleh UKM KUB Perintis Harapan Mandailing Natal Sumatera Utara. Jenis kopi yang diproduksi adalah Arabica, dimana UKM ini memiliki perkebunan sendiri yang tumbuh di ketinggian 1000-2000 mdpl. Keutamaan dari kopi Arabica ini dibandingkan dengan jenis lain adalah kopi dengan level premium dengan cita rasa dan aroma yang khas dari setiap seduhannya sehingga memberikan nuansa tanah mandailing. Lopo Mandailing Kopi memiliki struktur rantai pasok sebagai berikut : 


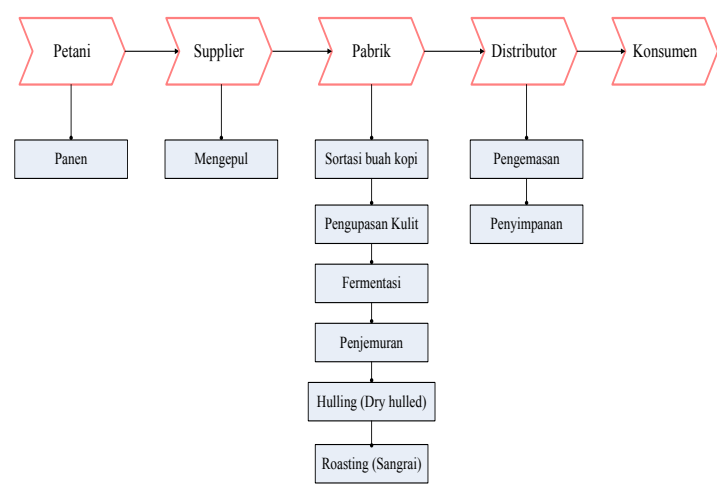

Gambar 1 Struktur Rantai Pasok Lopo Mandailing Kopi

Permasalahan di perusahaan ini adalah seringnya terjadi risiko pada rantai pasok baik dia risiko cacat pada bahan baku maupun produk, sehingga perlu dilakukan identifikasi terhadap aktivitas rantai pasoknya untuk mengetahui apa saja risiko yang terjadi, dimana risiko tersebut terjadi dan apa penyebab risiko tersebut terjadi. Berikut ini data risiko cacat yang ada di perusahaan

Tabel 1. Data Defect (cacat) Kopi Pada Proses Januari-Juni 2015

\begin{tabular}{|l|c|c|c|c|c|c|}
\hline \multicolumn{1}{|c|}{ Bulan } & $\begin{array}{c}\text { Bahan } \\
\text { baku }\end{array}$ & $\begin{array}{c}\text { Jumlah } \\
\text { cacat } \\
\text { defect })\end{array}$ & \multicolumn{4}{|c|}{ Keterangan cacat (\%/kg) } \\
\hline Januari & $25 \mathrm{~kg}$ & $3 \mathrm{~kg}$ & $6 \%$ & $6 \%$ & $7 \%$ & \\
\hline Februari & $26 \mathrm{~kg}$ & $4 \mathrm{~kg}$ & $7 \%$ & $6 \%$ & $8 \%$ & $8 \%$ \\
\hline Maret & $26 \mathrm{~kg}$ & $4 \mathrm{~kg}$ & $7 \%$ & $7 \%$ & $8 \%$ & $9 \%$ \\
\hline April & $26 \mathrm{~kg}$ & $3 \mathrm{~kg}$ & $9 \%$ & $7 \%$ & $10 \%$ & \\
\hline Mei & $25 \mathrm{~kg}$ & $3 \mathrm{~kg}$ & $7 \%$ & $6 \%$ & $9 \%$ & \\
\hline Juni & $25 \mathrm{~kg}$ & $4 \mathrm{~kg}$ & $8 \%$ & $9 \%$ & $6 \%$ & $7 \%$ \\
\hline
\end{tabular}

(Sumber : UKM KUB Perintis Harapan Mandailing Natal Sumut)

Tabel 2 Data Kopi Cacat (defect) Pada Distribusi Januari-Juni 2015

\begin{tabular}{|l|c|c|c|c|c|}
\hline \multirow{2}{*}{ Bulan } & \multirow{2}{*}{ Pengiriman } & \multicolumn{3}{|c|}{ Defect (cacat) } & \multirow{2}{*}{ Total } \\
\cline { 3 - 5 } & & $\mathbf{1 0 0} \mathbf{g r}$ & $\mathbf{2 5 0} \mathbf{g r}$ & $\mathbf{5 0 0} \mathbf{~ g r}$ & \\
\hline Januari & $20 \mathrm{~kg}$ & $5 \mathrm{pcs}$ & $4 \mathrm{pcs}$ & $4 \mathrm{pcs}$ & $13 \mathrm{pcs}$ \\
\hline Februari & $21 \mathrm{~kg}$ & $5 \mathrm{pcs}$ & $3 \mathrm{pcs}$ & $3 \mathrm{pcs}$ & $11 \mathrm{pcs}$ \\
\hline Maret & $22 \mathrm{~kg}$ & $7 \mathrm{pcs}$ & $4 \mathrm{pcs}$ & $4 \mathrm{pcs}$ & $15 \mathrm{pcs}$ \\
\hline April & $22 \mathrm{~kg}$ & $6 \mathrm{pcs}$ & $5 \mathrm{pcs}$ & $4 \mathrm{pcs}$ & $15 \mathrm{pcs}$ \\
\hline Mei & $21 \mathrm{~kg}$ & $6 \mathrm{pcs}$ & $3 \mathrm{pcs}$ & $3 \mathrm{pcs}$ & $12 \mathrm{pcs}$ \\
\hline Juni & $21,5 \mathrm{~kg}$ & $7 \mathrm{pcs}$ & $4 \mathrm{pcs}$ & $3 \mathrm{pcs}$ & $14 \mathrm{pcs}$ \\
\hline
\end{tabular}

(Sumber : UKM KUB Perintis Harapan Mandailing Natal Sumut)

Seringnya terjadi risiko cacat pada pada produk maupun bahan baku di perusahaan ini tentunya menimbulkan dampak buruk pada perusahaan salah satunya berdampak pada menurunnya penjualan Lopo Mandailing Kopi. Berikut data penjualan produk Lopo Mandailing Kopi disajikan dalam tabel :
Tabel 3 Data Penjualan Lopo Kopi Januari-Juni 2015

\begin{tabular}{|l|c|c|c|c|}
\hline \multicolumn{1}{|c|}{ Bulan } & Bandung & Yogyakarta & Pekanbaru & Total \\
\hline Januari & $7 \mathrm{~kg}$ & $7 \mathrm{~kg}$ & $6 \mathrm{~kg}$ & $20 \mathrm{~kg}$ \\
\hline Februari & $8 \mathrm{~kg}$ & $7 \mathrm{~kg}$ & $6 \mathrm{~kg}$ & $21 \mathrm{~kg}$ \\
\hline Maret & $8 \mathrm{~kg}$ & $8 \mathrm{~kg}$ & $7 \mathrm{~kg}$ & $22 \mathrm{~kg}$ \\
\hline April & $8 \mathrm{~kg}$ & $7 \mathrm{~kg}$ & $7 \mathrm{~kg}$ & $22 \mathrm{~kg}$ \\
\hline Mei & $9 \mathrm{~kg}$ & $6 \mathrm{~kg}$ & $6 \mathrm{~kg}$ & $21 \mathrm{~kg}$ \\
\hline Juni & $8 \mathrm{~kg}$ & $7,5 \mathrm{~kg}$ & $6 \mathrm{~kg}$ & $21,5 \mathrm{~kg}$ \\
\hline
\end{tabular}

Dari tabel di atas dapat dilihat bahwa penjualan Lopo Mandailing Kopi di 3 kota di Indonesia dari bulan Januari sampai Juni 2015 mengalami ketidakstabilan dan di bulan-bulan terakhir terjadi penurunan yang signifikan. Ini bisa dikatakan merupakan salah satu dari dampak risiko yang terjadi pada rantai pasok Lopo Mandailing Kopi.

Dalam proses produksinya, perusahaan Lopo Mandailing Kopi ini memiliki standar biji kopi yang bisa diolah. Ini akan sangat berpengaruh pada kualitas dan rasa kopi itu sendiri. Standar dari biji kopi yang bisa diolah adalah kadar air biji kopi $12 \%$, jika kadar air nya pas dan sesuai dengan standar maka akan didapatkan kualitas kopi terbaik dari setiap seduhannya. Kemudian cacat (defect) dari biji kopi ini maksimal $5 \%$ per kilogram nya. Jika terdapat biji kopi yang tidak memenuhi standar maka biji kopi tersebut akan dibuang atau dilakukan penjemuran ulang yang akan memakan waktu $3-4$ hari penjemuran.

\section{Rumusan Masalah}

Berdasarkan latar belakang permasalahan yang ada maka dapat ditentukan perumusan masalah yaitu mengidentifikasi risiko rantai pasok Lopo Mandailing Kopi dengan pendekatan sistem traceability.

\section{Tujuan Penelitian}

Tujuan yang dapat diambil dalam penulisan laporan ini adalah :

1. Mengidentifikasi terjadinya risiko dalam rantai pasok Lopo Mandailing Kopi.

2. Menganalisa penyebab terjadinya risiko.

\section{Batasan Masalah}

Agar penelitian ini lebih terfokus dan tidak menyimpang dari topik yang dipermasalahkan, maka perlu adanya batasan masalah. Batasan tersebut sebagai berikut :

1. Data penelitian diambil dari bulan Januari 2015 s/d Februari 2016.

2. Penelitian ini tidak memperhitungkan biaya. 


\section{Tinjauan Pustaka}

\section{Supply Chain Management (SCM)}

Supply chain management adalah pengintegrasian sumber bisnis yang kompeten dalam penyaluran barang, mencakup perencanaan dan pengelolaan aktivitas pengadaan dan logistik serta informasi terkait mulai dari tempat bahan baku sampai tempat konsumsi, termasuk koordinasi dan kolaborasi dengan jaringan mitra usaha (pemasok, manufaktur, pergudangan, transportasi, distribusi, retail, dan konsumen) untuk memenuhi kebutuhan pelanggan (Siahaya, 2013).

\section{Konsep SCM}

Supply chain management memiliki 4 konsep yaitu sebagai berikut (Siahaya, 2013) :

1. Mengintegrasikan dan mengsinkronkan pemasok, manufaktur dan distributor.

- Produk yang dihasilkan dan didistribusikan memiliki kualitas, jumlah, waktu dan tujuan.

- Mengoptimalkan biaya dan meningkatkan daya saing dan layanan pelanggan.

2. Mengurangi jumlah pemasok.

- Mengurangi ketidak seragaman, biaya tambahan, proses negosiasi dan waktu pelacakan (tracking).

- Perubahan kevenderungan dari konsep multiple supplier ke single supplier.

3. Kemitraan (partnership/strategic alliances).

- Supplier partnership merupakan kemitraan yang dapat menjamin kelancaran arus barang.

- Melaksanakan pengembangan secara terus menerus dalam efisiensi biaya dan mutu barang.

Kegiatan SCM mendekat ke sumber dan pelaksanaan pengadaan langsung ke produsen, tanpa melalui perantara yaang akan menambah biaya. Supplier dalam SCM berarti produsen, bukan perantara.

\section{System Traceability}

Traceability menurut kamus Oxford online adalah kata benda dari trace yang berarti penelusuran melalui investigasi. Investigasi yang dimaksud adalah kegiatan melacak asal usul entitas yang diwujudkan dalam pencatatan (Less, 2003 dikutip oleh Jaya, 2014). Sedangkan Codec Alimentarius Commision (CAC) mendefenisikan traceability adalah kemampuan untuk mengikuti perjalanan disetiap tahapan produksi, proses, dan distribusi (Jaya, 2014).

Traceability merupakan suatu sistem yang dapat meningkatkan transparansi dalam rantai supplai dalam mengurangi risiko klaim serla menemukan potensi risiko proses rantai pasok makanan. Traceability didefinisikan oleh ISO 9000:2000 sebagai kemampuan untuk menelusuri sejarah, aplikasi, atau lokasi dan catatan yang dapat menghubungkan produk dengan asal bahan dan sejarah proses produk, serta distribusi produk (ISO, 2000 dikutip oleh Jaya, 2014).

Sistem traceability di dalam rantai makanan merupakan jaringan yang dapat digambarkan, diidentifikasi, dan didokumentasikan pada tahapan proses produksi dari hulu (lahan pertanian) sampai hilir (produk ke konsumen) sehingga sistem traceability sangat efektif, efisien, dan tepat dalam mengikuti perjalanan pangan, di setiap tahapan proses produksi, dan distribusi (Becker, 2000 dikutip oleh Handayani, 2012). Banyak pakar meyakini traceability sudah menjadi satu metode yang efektif dalam menjamin keamanan makanan, kualitas makanan. Sehingga apabila terjadi suatu permasalahan dapat segera menelusuri kembali asal usul makanan tersebut sampai bisa diketahui sumber permasalahan bagian rantai suplai makanan yang mana menyebabkan permasalahan terjadi (Rabade, 2009 dikutip oleh Handayani, 2012). Selain itu traceability tidak hanya memberi jaminan extra keamanan makanan tetapi juga memberi transparansi rantai nilai konsumen (Fritz dkk, 2009 dikutip oleh Handayani, 2012).

\section{Risiko}

Beberapa defenisi akan dijelaskan di bawah ini beserta penjelasannya. Perlu diperingatkan bahwa subjek risiko begitu kompleks terdapat dalam berbagai bidang yang berbeda, sehingga tak mengherankan jika terdapat pengertian yang berbeda pula. Karena itu sebelum kita dapat menangani suatu risiko maka terlebih dahulu kita harus mengetahui dengan tepat apa yang dimaksudkan dengan risiko dalam kasus yang ditangani itu. Vaughan (1978) mengemukakan beberapa defenisi risiko dapat kita lihat berikut ini (Darmawi, 2014) :

1. Risk is the chance of loss (Risiko adalah kans kerugian)

Chance of loss biasanya digunakan untuk menunjukkan suatu keadaan dimana terdapat suatu keterburukan (exporsure) terhadap kerugian atau suatu kemungkinan kerugian. Sebaliknya jika disesuaikan dengan istilah yang dipakai dalam statistik, maka "chance" sering dipergunakan untuk menunjukkan tingkat probabilitas akan munculnya situasi tertentu.

2. Risk is the possibilitty of loss (Risiko adalah kemungkinan kerugian)

Istilah "possibility" berarti bahwa probabilitas sesuatu peristiwa berada di antara nol dan satu. Defenisi ini barangkali sangat mendekati dengan pengertian risiko yang dipakai sehari- 
hari. Akan tetapi defenisi ini agak longgar, tidak cocok dipakai dalam analisis secara kuantitatif.

3. Risk is uncertainty (Risiko adalah ketidakpastian)

Tampaknya ada kesepakatan bahwa risiko berhubungan dengan ketidakpastian (uncertainty) yaitu adanya risiko, karena ketidakpastian. Karena itulah ada penulis yang mengartikan bahwa risiko itu sama artinya dengan ketidakpastian.

\section{Metode Penelitian}

Metodologi digunakan untuk mengarahkan dan mempermudah proses analisis dalam mencari solusi dalam memecahkan masalah. Yaitu dengan menguraikan seluruh kegiatan yang dilaksanakan selama kegiatan berlangsung dari awal proses penelitian sampai akhir. Dengan mengikuti tahapan-tahapan dalam metodologi, diharapkan hasil ini akan menjadi lebih baik. Metodologi penelitian ini disajikan dalam bentuk diagram alir atau flowchart.

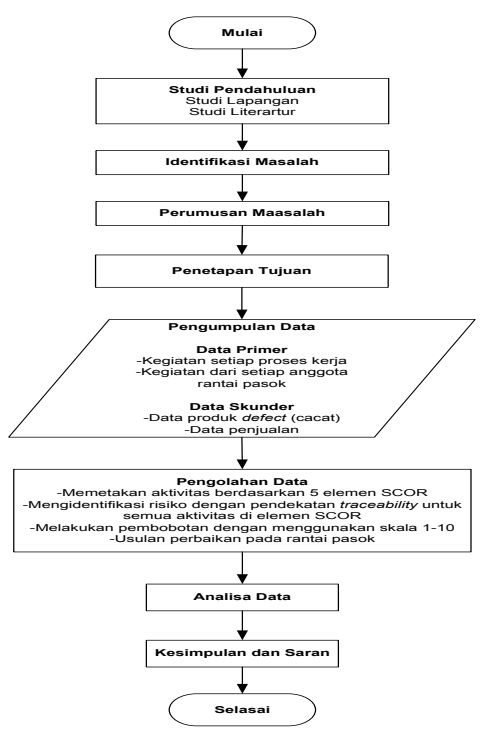

Gambar 2 Flowchart Metodologi Penelitian

\section{Hasil dan Pembahasan}

\section{Memetakan aktivitas berdasarkan 5 elemen SCOR}

Dalam model Supply Chain Operation Reference (SCOR) terdapat 5 elemen yaitu plan, source, make, delivery, dan return. plan menyeimbangkan sumber daya/persediaan, source berhubungan dengan penyediaan bahan baku, make merubah bahan baku menjadi bahan jadi, delivery berhubungan dengan proses pengiriman barang, dan return adalah proses melakukan atau menerima pengembalian karena suatu alasan. Pemetaan aktivitas diperoleh dari wawancara dengan pihak perusahaan.

Tabel 4 Pemetaan Aktivitas Berdasarkan 5 Elemen SCOR

\begin{tabular}{|l|l|l|}
\hline \multirow{2}{*}{ Pelaku } & \multicolumn{1}{|c|}{$\begin{array}{c}\text { Area } \\
\text { Proses } \\
\text { Bisnis }\end{array}$} & \multicolumn{1}{c|}{ Aktivitas } \\
\hline \multirow{2}{*}{ Petani } & Source & Memetik/memanen biji kopi \\
\cline { 2 - 3 } & Delivery & Mengirimkan biji kopi ke pemasok \\
\hline \multirow{2}{*}{ Pemasok } & Source & Peneriman dan penyortiran biji kopi \\
\cline { 2 - 3 } & Make & Mengumpulkan biji kopi \\
\hline
\end{tabular}

Tabel 4 Pemetaan Aktivitas Berdasarkan 5 Elemen SCOR (Lanjutan)

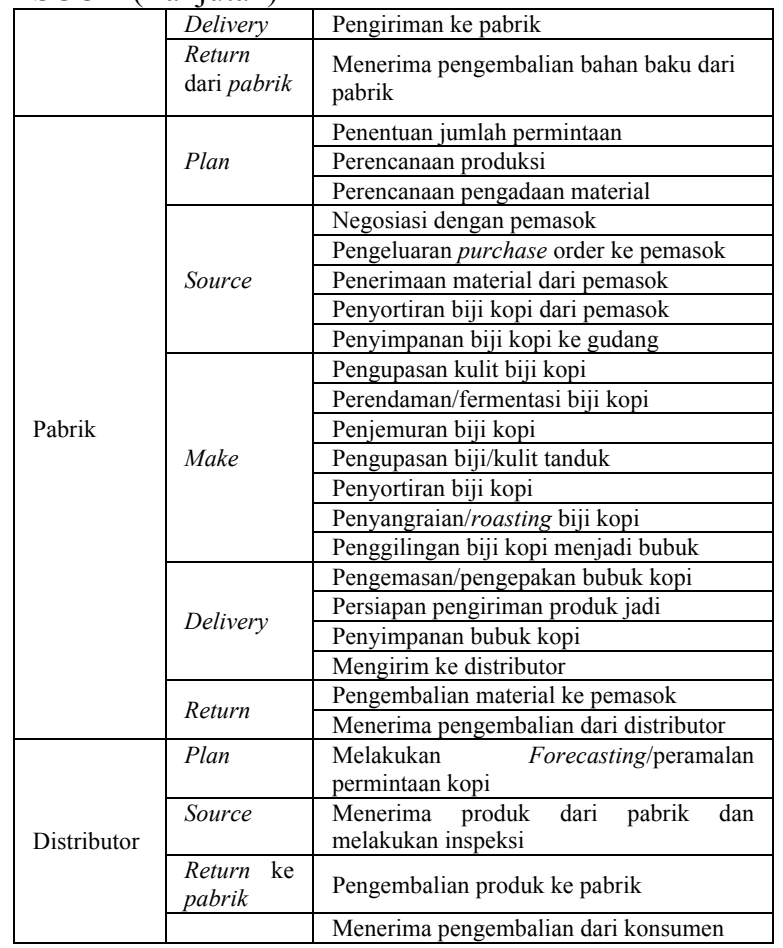

Setelah diidentifikasi terhadap aktivitas yang ada dalam rantai pasok, maka didapatkan hasil kejadian risiko dari aktivitas tersebut. Berikut disajikan dalam bentuk tabel :

Tabel 5 Identifikasi Risiko Dengan Traceability

\begin{tabular}{|c|c|c|}
\hline $\begin{array}{c}\text { Area } \\
\text { Proses } \\
\text { Bisnis }\end{array}$ & Aktivitas & Risk Event \\
\hline \multirow{2}{*}{ Source } & \multirow{2}{*}{ Memetik/memanen biji kopi } & Petik kurang matang \\
\hline & & Terdapat hama pada biji kopi \\
\hline Delivery & Mengirimkan biji kopi ke pemasok & Bahan baku cacat dalam perjalanan \\
\hline \multirow{2}{*}{ Source } & \multirow{2}{*}{ Penerimaan dan penyortiran biji kopi } & Keterlambatan penerimaan bahan baku \\
\hline & & Ketidak sesuaian barang yang dipesan \\
\hline Make & Mengumpulkan biji kopi & Barang rusak ketika pengumpulan \\
\hline \multirow{2}{*}{ Delivery } & \multirow{2}{*}{ Pengiriman ke pabrik } & Keterlambatan pengiriman \\
\hline & & $\begin{array}{l}\text { Barang cacat dalam perjalanan } \\
\end{array}$ \\
\hline \multirow{3}{*}{ Plan } & Penentuan jumlah permintaan & Ketidak sesuaian dengan permintaan \\
\hline & Perencanaan produksi & Keterlambatan dalam produksi \\
\hline & Perencanaan pengadaan material & Ketidaksesuaian material yang dipesan \\
\hline \multirow{3}{*}{ Source } & Penerimaan material dari pemasok & Keterlambatan penerimaan material \\
\hline & Penyortiran biji kopi dari pemasok & $\begin{array}{l}\text { Ketidak sesuaian kualitas dan jumlah yang di } \\
\text { pesan }\end{array}$ \\
\hline & Penyimpanan biji kopi ke gudang & Biji kopi rusak di gudang \\
\hline \multirow{5}{*}{ Make } & Pengupasan kulit biji kopi & Biji kopi pecah pada saat pengupasan kulit \\
\hline & \multirow{2}{*}{ Perendaman/fermentasi biji kopi } & kualitas biji kopi rusak ketika fermentasi \\
\hline & & Kadar air tinggi \\
\hline & Penjemuran biji kopi & Biji kopi terkena air hujan saat penjemuran \\
\hline & Pengupasan biji/kulit tanduk & Biji kopi pecah \\
\hline
\end{tabular}


Tabel 5 Identifikasi Risiko Dengan Traceability (Lanjutan)

\begin{tabular}{|c|c|c|}
\hline $\begin{array}{l}\text { Area } \\
\text { Proses } \\
\text { Bisnis }\end{array}$ & Aktivitas & Risk Event \\
\hline & Penyortiran biji kopi & Ketidak sesuaian dengan yang dipesan \\
\hline & Penyangraian/roasting biji kopi & Biji kopi rusak karena terlalu panas \\
\hline \multirow{4}{*}{ Delivery } & $\begin{array}{l}\text { Pengemasan/pengepakan bubuk } \\
\text { kopi }\end{array}$ & Kemasan rusak \\
\hline & Persiapan pengiriman produk jadi & Kesalahan pengangkutan produk \\
\hline & Penyimpanan bubuk kopi & Produk rusak di tempat penyimpanan \\
\hline & Mengirim ke distributor & Produk cacat dalam perjalanan \\
\hline Plan & $\begin{array}{l}\text { Melakukan Forecasting/peramalan } \\
\text { permintaan kopi }\end{array}$ & Kesalahan dalam peramalan permintaan \\
\hline \multirow{3}{*}{ Source } & \multirow{3}{*}{$\begin{array}{l}\text { Menerima produk dari pabrik dan } \\
\text { melakukan inspeksi }\end{array}$} & Keterlambatan penerimaan \\
\hline & & Ketidak sesuaian barang dengan pesanan \\
\hline & & Produk diterima dalam keadaan cacat \\
\hline
\end{tabular}

Dengan diketahuinya kejadian risiko maka selanjutnya dapat diidentifikasi penyebab risiko yaitu disajikan dalam bentuk tabel sebagai berikut :

Tabel 6 Identifikasi Penyebab Risiko (Risk Agen)

\begin{tabular}{|c|c|c|}
\hline No. & Kejadian Risiko (Risk Event) & Penyebab Risiko (Risk Agen) \\
\hline 1 & Petik kurang matang & Kurang memperhatikan kematangan buah \\
\hline 2 & Terdapat hama pada biji kopi & $\begin{array}{l}\text { Kurang memperhatikan perawatan tanaman } \\
\text { kopi }\end{array}$ \\
\hline 3 & Bahan baku cacat dalam perjalanan & Tidak ada prosedur dalam proses pengiriman \\
\hline 4 & Keterlambatan penerimaan bahan baku & $\begin{array}{l}\text { Ketidak sesuaian permintaan dengan yang } \\
\text { dipanen }\end{array}$ \\
\hline 5 & Ketidak sesuaian barang yang dipesan & Tidak memperhatikan standar kualitas biji kopi \\
\hline 6 & Barang rusak ketika pengumpulan & Kurang memperhatikan prosedur kerja \\
\hline & Keterlambatan pengiriman & Alat transportasi bermasalah \\
\hline 8 & Barang cacat dalam perjalanan & Tidak ada prosedur \\
\hline 9 & Ketidak sesuaian dengan permintaan & Kesalahan dalam menyampaikan informasi \\
\hline 10 & Keterlambatan dalam produksi & $\begin{array}{lllll}\begin{array}{l}\text { Ketidak sesuaian bahan } \\
\text { permintaan }\end{array} & \text { baku dengan } \\
\end{array}$ \\
\hline 11 & Ketidaksesuaian material yang dipesan & $\begin{array}{l}\text { Tidak memperhatikan standar kualitas bahan } \\
\text { baku }\end{array}$ \\
\hline 12 & Keterlambatan penerimaan material & Keterlambatan pengiriman dari pemasok \\
\hline 13 & $\begin{array}{l}\text { Ketidak sesuaian kualitas dan jumlah } \\
\text { yang di pesan }\end{array}$ & $\begin{array}{lll}\begin{array}{l}\text { Tidak memperhatikan } \\
\text { permintaan }\end{array} & \text { standar } & \text { kualitas } \\
\end{array}$ \\
\hline 14 & Biji kopi rusak di gudang & Tidak ada prosedur penyimpanan bahan baku \\
\hline 15 & $\begin{array}{l}\text { Biji kopi pecah pada saat pengupasan } \\
\text { kulit }\end{array}$ & $\begin{array}{l}\text { Tidak memperhatikan prosedur penggunaan } \\
\text { mesin pulper }\end{array}$ \\
\hline 16 & $\begin{array}{lcccc}\begin{array}{l}\text { Kualitas b biji } \\
\text { fermentasi }\end{array} & \text { kopi } & \text { rusak } & \text { ketika } \\
\end{array}$ & Fermentasi terlalu lama \\
\hline 17 & Kadar air tinggi & Tidak ada prosedur dalam penjemuran \\
\hline 18 & Biji kopi rusak saat penjemuran & Terkena air hujan \\
\hline 19 & Biji kopi pecah & $\begin{array}{l}\text { Tidak memperhatikan prosedur penggunaan } \\
\text { mesin hulling }\end{array}$ \\
\hline 20 & Ketidak sesuaian dengan yang dipesan & Tidak memperhatikan standar kualitas produk \\
\hline 21 & Biji kopi rusak saat penyangraian & Penyangraian terlalu panas dan terlalu lama \\
\hline 22 & Kemasan rusak & Kurang memperhatikan prosedur pengemasan \\
\hline 23 & Kesalahan pengangkutan produk & Kesalahan letak penyimpanan \\
\hline 24 & Produk rusak di tempat penyimpanan & Tidak ada prosedur penyimpanan produk \\
\hline
\end{tabular}

Ditahap evaluasi risiko dilakukan penentuan prioritas risiko menggunakan konsep diagram pareto. Yaitu dengan mempertimbangkan nilai ARP dari setiap penyebab risiko yang diurutkan dari nilai terbesar hingga nilai terkecil. Sehingga diketahui penyebab risiko mana saja yang masuk kategori risiko tinggi. Lebih jelasnya dapat dilihat dari diagram pareto berikut :

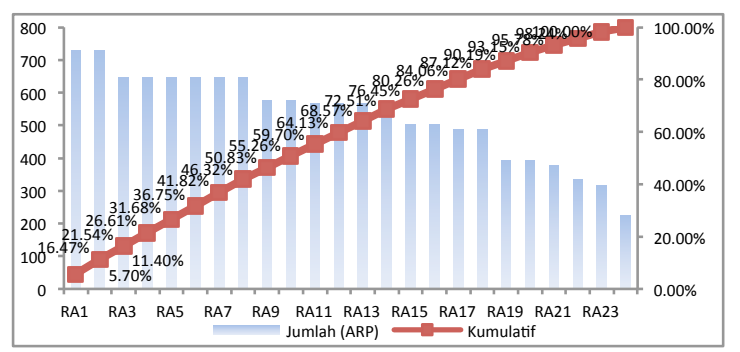

Gambar 4.1 Diagram Pareto

Berdasarkan diagram pareto di atas dapat diketahui bahwa sesuai konsep 80:20, maka yang termasuk ke dalam $80 \%$ dan menjadi prioritas adalah 16 penyebab risiko yaitu sebagai berikut :

1. Tidak memperhatikan prosedur penggunaan mesin pulper

2. Tidak memperhatikan prosedur penggunaan mesin hulling

3. Kurang memperhatikan perawatan tanaman kopi

4. Alat transportasi bermasalah

5. Tidak memperhatikan standar kualitas bahan baku

6. Keterlambatan pengiriman dari pemasok

7. Tidak memperhatikan standar kualitas permintaan

8. Tidak memperhatikan standar kualitas produk

9. Ketidak sesuaian bahan baku dengan permintaan

10. Tidak ada prosedur dalam penjemuran

11. Kurang memperhatikan kematangan buah

12. Kurang memperhatikan prosedur kerja

13. Tidak ada prosedur penyimpanan bahan baku

14. Tidak ada prosedur penyimpanan produk

15. Terkena air hujan

16. Penyangraian terlalu panas dan terlalu lama

\section{Kesimpulan}

Berdasarkan hasil yang diperoleh dan berdasarkan penetapan tujuan yang ingin dicapai maka, dapat disimpulkan hasil penelitian yang telah dilakukan sebagai berikut :

1. Dari hasil identifikasi berdasarkan pendekatan sistem traceability yaitu terdapat total 29 kejadian risiko (risk event) yang ada pada rantai pasok Lopo Mandailing Kopi. Dimana keseluruhan kejadian risiko diketahui berdasarkan pemetaan semua aktivitas ke dalam 5 elemen SCOR.

2. Berdasarkan hasil identifikasi terhadap kejadian risiko (risk event) maka didapatkan total 24 penyebab risiko (risk agen). Dan sesuai konsep 80:20 diagram pareto, maka terdapat 16 penyebab risiko yang menjadi prioritas untuk dilakukan penanganan.

\section{Saran}

Berdasarkan penelitian yang telah dilakukan terdapat beberapa saran yang dapat peneliti diberikan yaitu sebagai berikut :

1. Diharapkan untuk kepala bidang masingmasing di perusahaan agar meningkatkan pengawasan terhadap kinerja karyawannya agar terhindar dari kelalaian yang dapat mengakibatkan kejadian risiko bagi perusahaan. Dan juga kepada masing-masing 
pelaku rantai pasok yang terlibat agar lebih mengutamakan tugasnya masing-masing dibanding yang lain sehingga dapat meningkatkan produktifitas. Dan perusahaan semestinya membuat SOP pada setiap aktivitas di dalam rantai pasoknya.

2. Saran untuk peneliti selanjutnya yaitu agar lebih mengembangkan teori-teori dan metodemetode yang digunakan, jangan hanya terpaku pada satu objek saja, yaitu dengan mengkombinasikan beberapa metode sehingga nantinya juga bisa digunakan pada penelitian bidang yang lain.

\section{Ucapan Terima Kasih}

Penulisan penelitian ini tidak lepas dari bantuan beberapa pihak. Untuk itu penulis mengucapkan terima kasih kepada :

1. Ibu Misra Hartati, ST., MT. selaku pembimbing utama, atas ide, saran dan masukan yang membangun sehingga terselesaikannya Tugas Akhir ini menjadi lebih baik.

2. Bapak Ismu Kusumanto, ST., MT. dan Ibu Tengku Nurainun, ST., M.T. selaku penguji 1 dan penguji 2.

3. Bapak Riki Wijayadi selaku pembimbing diperusahaan UKM KUB Perintis Harapan Sumut.

\section{Daftar Pustaka}

Darmawi, Herman. "Manajemen Risiko." Edisi 1, halaman 17-30. PT. Bumi Aksara, Jakarta. 2014

Handayani, Iryaning. "Identifikasi Risiko Rantai Pasok Berbasis Sistem Traceability Pada Minuman Sari Apel.” Spektrum Industri. Vol. 11, No. 2, halaman 117-242, 2013

Handayani, Iryaning. "Risiko rantai Pasok Minuman Sari Apel Dalam Perspektif Sistem Traceability." Jurnal Taknik Industri. Vol. 9, No. 1, halaman 57-60, januari 2014

Handayani, Iryaning, dan Iwan Vanany. "Pemetaan Aktivitas Rantai Pasok Dalam Membangun Sistem Traceability Pada Industri Sari Apel." Jurnal Teknik Industri. Halaman A-30-2-A-30-7, Juli 2012

Jaya, Rachman, dkk. "Review Sistem Traceability Pada Rantai Pasok Produk Pertanian," Jurnal Teknilogi dan Mutu Industri. Vol. 1, No. 1, halaman 35-40, 2014

Kurniawan, Rifki, dan Raymond H. Rumambi. "Peran Strategi Supply Chain Management Dalam Industri Hulu Minyak Dan Gas Bumi." Jurnal Penelitian. Vol. 1, halaman 4-9, 2015
Luthfiana, Chairunisa, dan Rahadian Perdana. "Pengukuran Performasi Supply Chain Dengan Pendekatan Supply Chain Operation Reference (SCOR) Dan Analytical Hierarchy Process (AHP)." Jurnal Teknik Industri. Halaman 59-62, 2012

Peraturan Menteri Pertanian Republik Indonesia. "Pedoman Panen, Pascapanen, Dan Pengelolaan Bangsal Pascapanen Holtikultura Yang Baik.” PERMENTAN. No. 73, 2013

Raharjo, Hartono. "Penentuan Rute Pengiriman Kayu Untuk Meminimumkan Biaya Distribusi Dengan Metode Clark And Wright Saving Heuristic." Jurnal Teknik Industri. Halaman 1-2, Desember 2014

Saputra, Bagus. "Performasi Kinerja Perusahaan Dengan Menggunakan Metode Supply Chain Operation Reference (SCOR)." Jurnal Teknik Industri. Halaman 20-25, Agustus 2013

Saputra, Hendra, dan Prima Fithri. "Perancangan Model Pengukuran Kinerja Green Supply Chain Pulp Dan Kertas."Jurnal Optimasi Sistem Industri. Vol. 11, No. 1, halaman 193-195, April 2012

Siahaya, Willem. "Sukses Supply Chain Management Akses Demand Chain Management." Halaman 7-26. In Media, Jakarta. 2013

Subroto, Budiarto. "Pemasaran Industri Bsiness to Business Marketing." Halaman 199-203. C.V. Andi Offset, Yogyakarta. 2011

Utari, Retno, dan Imam Baihaqi. "Perancangan Strategi Mitigasi Resiko Supply Chain Di PT Atlas Copco Nusantara Dengan House Of Risk." Jurnal Teknik Industri. Halaman B-19-2, Januari 2015 